\title{
EL MALTRATO INFANTIL EN LA NOVELA MLAU DE GALDÓS
}

\section{Child Abuse in the Novel Miau by Galdós}

\author{
NYDIA JEFFERS \\ Elkins High School, Arkansas \\ nydiarvargas@gmail.com \\ ORCID ID: 0000-0002-8006-7058
}

Recibido: 29-07-2021 / Aceptado: 7-10-2021 DOI: https://doi.org/10.51743/cilh.vi47.225

El niño Luis Cadalso, en la novela Miau (1888) de Benito Pérez Galdós, experimenta sueños, pesadillas, ilusiones y alucinaciones visuales y auditivas que exponen la angustia de un niño maltratado, víctima de la violencia, de la negligencia educativa y de la privación afectiva. Este trabajo analiza los síntomas del estrés agudo y del posterior estrés postraumático que sufre tras el cese laboral de su abuelo.

PALABRAS CLAVE: Maltrato infantil; trauma; trastornos por estrés; Galdós;

Miau.

ABSTRACT

The child Luis Cadalso, in the novel Miau (1888) by Benito Pérez Galdós, experiences dreams, nightmares, visual delusions, and visual and auditory hallucinations that expose the anguish of an abused child, victim of violence, in addition to educational negligence and emotional deprivation. This article analyses the symptoms of acute stress and the subsequent post-traumatic stress that he suffers after his grandfather stops working.

KEY WORDS: Child abuse; Trauma; Stress Disorders; Galdós; Miau. 


\title{
EL MALTRATO INFANTIL EN LA NOVELA MIAU DE GALDÓS
}

\author{
NYDIA JEFFERS \\ Elkins High School
}

ENTRE LOS TRAUMAS psicológicos que expone el escritor Benito Pérez Galdós en su novela Miau [1888], situada en Madrid en marzo y abril de 1878, destaca el cese en el cargo de Ramón Villaamil. Para el funcionario de sesenta años, el cese es una herida grave que hace peligrar su vida. El nieto de nueve años, Luis Cadalso, revive el trauma personal del abuelo experimentando unas visiones en las que, a nuestro juicio, imagina que habla con «Dios» con el fin de resolver la colocación del abuelo en el Ministerio de Hacienda. En realidad, consideramos que habla con la voz de su subconsciencia, que le ayuda a procesar varios tipos de abusos que soporta directamente a raíz del cese, como son, el acoso escolar, el maltrato físico y verbal, así como las privaciones que sufre de tipo afectiva, educativa y económica. El peor abuso ocurre al final de la novela. Luis cree que el cese del abuelo ha puesto furiosa a la familia y que, por eso, su tía lo ha atacado: "-Mi abuelo furioso porque no le colocan y mi abuela lo mismo, y mi tía Abelarda también. Y mi tía Abelarda no puede ver a mi papá, porque mi papá le dijo al ministro que no colocara a mi abuelo. Y como no se atreve con mi papá, porque puede más que ella, la emprendió conmigo» [Pérez Galdós, 1907: 
386]. Después del asalto físico y verbal de Abelarda, y como «mensajero de las terribles ansiedades, tristezas e impaciencias de su abuelo» [Pérez Galdós, 1907: 19], Luis desea que su abuelo se muera y el abuelo se suicida.

\section{TESIS Y REVISIÓN BIBLIOGRÁFICA}

Se propone comparar los síntomas y signos que se describen en la novela Miau para el protagonista Luis Cadalso con los criterios de diagnóstico del trastorno de ansiedad, que el Manual de trastornos mentales de la Asociación Americana de Psiquiatría denomina trastorno por estrés agudo, al primer mes después del trauma del cese, y trastorno por estrés postraumático durante el segundo mes que cubre la novela [2014]. Después de definir los síntomas de los trastornos, se describe la evolución de los mismos en tres fases de estrés donde se nota una progresiva pérdida de empatía por el valor de la vida de su abuelo, reducida a recuperar el trabajo ministerial.

En particular, la esperanza por la vida del abuelo se inicia con la idea de «Dios» en sus sueños; luego, decae con la ausencia de «Dios» en sus alucinaciones; y desaparece con la determinación del cese que «Dios» le comunica en la pesadilla final. Estas tres fases se relacionan con siete situaciones de abuso. La primera fase, de trastorno por estrés agudo, se conecta con la explotación laboral del niño, la negligencia educativa, el acoso escolar, el acoso verbal y el maltrato del maestro. La segunda fase, de trastorno por estrés postraumático, comprende la carencia afectiva de su padre y abuelo, además de la exposición a la enfermedad y muerte de su compañero de colegio y acosador Paco Ramos. La tercera fase, también de estrés postraumático, abarca el terror a la crucifixión de Cristo en la iglesia, y la pérdida de apego por el abuelo.

Es conocido el interés de Galdós por la Medicina como forma de documentar sus novelas. Sebastián de la Nuez y Joseph Schraibman 
recogen en notas y cartas el dato de que el autor de la novela visitaba enfermos, como "sonámbulos», del pediatra y director de manicomio Manuel Tolosa Latour [1967: 285]. Galdós escribe un prólogo a un libro de Tolosa donde reconoce la "ciencia experimental y caritativa» para «atender al niño enfermo y defenderle de la muerte» [1889: 3]. En cuanto a su admiración por la Ciencia, afirma que «vive en continuo flirtation con la medicina» por su capacidad de diagnóstico de «los temperamentos y desórdenes funcionales» [1889: 8] "archivando experiencias y casos que nos serían muy útiles a los que tenemos por oficio el pintar la vida y el dolor» [1889: 7].

En términos decimonónicos, Luis sufre de histeria, condición relacionada con el trauma. Eduardo Cazabat [2004] indica que el psiquiatra francés Paul Briquet fue quien primero relacionó el trauma con la histeria, la cual fue descrita como disociación de la memoria por Pierre Janet. Cazabat aclara que Briquet y Janet sentaron las bases del diagnóstico de los trastornos por estrés, tanto el agudo, que surge al primer mes de un trauma, como el postraumático, que aparece al segundo mes. Los dos trastornos comparten los criterios de diagnóstico. Se propone explicar la fisiología de los «síntomas precursores» [Pérez Galdós, 1907: 28] de las visiones de «Dios», referidas como pavor, desmayo y sueño, como ataques de pánico. Los síntomas de intrusión se presentan con sueños y pesadillas recurrentes. El terror al Cristo se explica como síntoma de evitación del trauma, persistente los dos meses. Las alteraciones emocionales consisten en arrebatos de ira y ataques de pánico. El último criterio incluye la alteración cognitiva del nieto al pensar que no quiere que su abuelo viva porque así se lo ha comunicado «Dios» en un sueño. El abuelo, por su parte, cree que debe suicidarse porque así se lo ha avisado su nieto. Respecto a este criterio, hay que aclarar que los trastornos por estrés explicarían el pensamiento destructivo, pero no la parte del delirio mediante el cual abuelo y nieto confunden los sueños con apariciones divinas.

Harriet Turner [1998] asegura que Galdós consultaba los estudios 
clínicos de José Armangué y Tuset, que incluye la alucinación como síntoma de la locura o la enajenación mental. El maestro de Armangué, Juan Giné y Partagás [1876], concibe la enajenación mental como una «afección cerebral, generalmente crónica, apirética y caracterizada por desórdenes de la sensibilidad, la inteligencia y la voluntad e incapacidad para dominar sentimientos o ideas delirantes» [1876: 49]. Augustin Grisolle define el síntoma de la alucinación como «la sensación producida sin impresión exterior» [1857: 222]. Las alucinaciones serán clave para comprender la segunda fase de estrés de Luis. Antes de definir y explicar fase a fase los trastornos de estrés, es conveniente repasar el maltrato infantil, factor de riesgo principal en el desarrollo de estos trastornos.

\section{RECUERDO DEL MALTRATO POR EL NIÑO}

El protagonista de nueve años, Luis Cadalso, conoce el acoso verbal, y presencia el daño psicológico que inflige a su abuelo, quien lo cuidaba junto a sus tías porque su padre lo había abandonado y su madre había muerto a los dos años. Villaamil, funcionario del Ministerio de Hacienda en Madrid, solo necesita trabajar dos meses más en el cargo de jefe económico para recibir los cuatro quintos de su sueldo como jubilación. Con el relevo de presidentes del Estado en marzo de 1878, el ministro de Hacienda lo deja cesante. Entonces, pierde el sueldo y el derecho a la jubilación. El abuelo ha sido un funcionario competente y honrado, pero su esposa ha malgastado sus ingresos. Ha escrito cuatro libros para sanear el presupuesto general del Estado, pero su yerno le dice al ministro que el cesante tiene un trastorno mental. El trauma se agrava cuando su yerno, Víctor Cadalso, que ha robado al Estado, consigue un ascenso en el Ministerio por relaciones amorosas con una aristócrata. El acoso verbal se extiende a la oficina, donde el funcionario Guillén dibuja unas caricaturas que titula «El señor de Miau, meditando sus planes de 
Hacienda» [Pérez Galdós, 1907: 215] y a Víctor le hace gracia la burla a su suegro. Como su abuelo, Luis es insultado con el apodo «Miau» o «cara de gato» [Pérez Galdós, 1907: 82] por su compañero de clase Paco Ramos y el maestro. Además, es explotado por la abuela como cartero e ignorado por la familia, excepto a la hora de acostarse, cuando lo miman sus tías Abelarda y Milagros porque le dan miedo las pesadillas que suele tener. Luis es privado de asistir al colegio para pedir limosna en su oficio de repartir las cartas escritas por el abuelo a amigos para que le presten dinero.

En la escuela, tiene dificultades para concentrarse y no puede rendir. Luis es maltratado físicamente por el maestro, que también lo llama «Miau», y le obliga a visitar el funeral de cuerpo presente de un compañero que muere de tifus. En la iglesia de Monserrat, el niño está expuesto a la violencia gráfica de la crucifixión de Cristo y se esfuerza por no mirar la imagen para evitar recordar el trauma de su abuelo. Luis es asaltado por su tía, y a los dos años por su madre, porque ambas fueron maltratadas psicológicamente por Víctor, negándoles sus infidelidades a la vez que les prometía amor eterno. Finalmente, Víctor vende su hijo a su hermana por resolver un pleito que tenía con su cuñado. El abuelo lleva al nieto a la casa de Quintina. El nieto incita a que su abuelo se quite la vida como instrucción divina, y el abuelo, que había comprado un arma, se pega un disparo.

\section{DEFINICIÓN DE LOS TRASTORNOS POR ESTRÉS AGUDO Y POSTRAUMÁTICO}

\section{SÍNTOMAS FISIOLÓGICOS}

Primero, la activación de síntomas fisiológicos de los trastornos por estrés incluye los ataques de pánico, con mareos, escalofríos y sensación de ahogo, y las alteraciones en el sueño, que le hacen quedarse 
dormido durante el día y fuera de casa. Su cuerpo es sitio de ahorcamiento, como denota su apellido Cadalso. Al oír que tiene la culpa por no saberse la lección de Gramática e inculparse por el cese de su abuelo, «la congoja de Cadalsito fue tan grande, que creyó le apretaban la garganta con una soga y le estaban dando garrote» [Pérez Galdós, 1907: 89]. Esta ansiedad se hace patente en lo que el narrador llama «síntomas precursores» [Pérez Galdós, 1907: 103] cada vez que necesita hablar con «Dios», como describen estos dos ejemplos: (1) «Empezóle a Cadalsito la consabida desazón; se le iba el conocimiento de las cosas presentes, se mareaba, se desvanecía, le entraba el misterioso sobresalto, que era en realidad pavor de lo desconocido; y apoyando la frente en una enorme piedra que próxima tenía, se durmió como un ángel» [Pérez Galdós, 1907: 86]; y (2) «En efecto, a Cadalsito le daba de tiempo en tiempo una desazón singularísima, que empezaba con pesadez de cabeza, sopor, frío en el espinazo, y concluía con la pérdida de toda sensación y conocimiento» [Pérez Galdós, 1907: 28]. En muchos otros ejemplos, el narrador repite la misma mezcla de síntomas fisiológicos, los cuales preceden a los sueños y alteraciones visuales.

\section{SÍNTOMAS INTRUSIVOS}

Segundo, los síntomas intrusivos de los trastornos por estrés tienen lugar en forma de cinco pesadillas, cinco alucinaciones, dos sueños compensatorios y una ilusión visual. En las pesadillas, sueña, repetidamente, con un «Dios» que le culpa del cese del abuelo por no rendir en la escuela. De acuerdo con Magali Velasco, los diálogos con el supuesto «Dios» son una mezcla de angustia y alivio [2004: 76], por lo que las dos primeras visiones se pueden denominar semipesadillas. Primero, confunde a un mendigo ciego con «Dios», que le hace culpable del cese triste de su abuelo porque no se sabe la lección. Luego, «Dios» le reprocha el no estudiar, pero le hace un regalo 
en forma de anillos que parecen de oro y piedras preciosas y le halaga por pelearse con Paco. A continuación, después de ver a Paco enfermo y opinar que es castigo de «Dios», hablando alto en otro sueño angustioso, Luis actúa como si estuviera hablando con su tía Abelarda, que también habla durante su pesadilla, pero ambos sueñan con sus acosadores, Paco y Víctor, respectivamente. Posteriormente, dormido en el Congreso, y después de que fallece Paco, aquejado de tifus, Luis tiene una pesadilla con Paco, que lo insulta cuando «Dios» no lo ve. Por último, Luis culpa al ministro del cese del abuelo y responsabiliza a su padre del maltrato recibido por Abelarda. El niño imagina que «Dios» devuelve la bola azul del mundo a su sitio, fuera del alcance de Paco, que pretendía ahogar al mundo entero, con Luis dentro, se entiende. «Dios» castiga a Paco con un encierro. En esta pesadilla, acepta el cese y la muerte de su abuelo como una decisión divina, por lo que dice a su abuelo que «Dios» le manda morir, proyectando en «Dios» el deseo autodestructivo que presiente en su abuelo.

Entre las alucinaciones, en un síntoma disociativo de desrealización o sentido irreal del entorno, Luis ve insectos en las letras de su libro de Gramática, como efecto negativo del acoso escolar y efecto análogo al acoso personal a su abuelo. Además, ve flotar el cuerpo y el ropaje de «Dios», pero no la cara. Después de notar la pena de su abuelo por no aparecer en la nueva plantilla de personal, Luis se enfada primero consigo mismo por no estudiar en medio del catarro y luego con «Dios» por no curarlo para que pueda ayudar a colocar a su abuelo estudiando. En otro momento, cree ver a «Dios» en la iglesia caminando por la sacristía. Tras una pesadilla, después de conocer el ascenso de su padre, que confirma el cese definitivo de su abuelo, experimenta una alucinación con Cristo crucificado, en lugar de la deseada imagen de «Dios», que no tiene las lesiones graves que son símbolos de la victimización de su abuelo y de sí mismo. 
En un sueño compensatorio, también relacionado con la responsabilidad moral de ayudar a su abuelo, ve el cuerpo de su abuelo al pie de la cama encarnado en el cuerpo estereotipado que representa a «Dios» en la estampa religiosa, escribiendo una carta al ministro de Hacienda, acto que luego reporta a su abuelo. Las innumerables cartas que el abuelo escribe para pedir ayuda se vuelven "cuatrillones» en el sueño; la mano de su abuelo se hace «inmortal» en la visión de «Dios» [Pérez Galdós, 1907: 49].

En otro sueño compensatorio, Luis quiere enseñar su álbum de sellos a «Dios» y sueña consigo mismo como soñador, pero no ve a «Dios». La ausencia de «Dios» la justifica, a su modo de ver, porque «Dios» está asistiendo el lecho de muerte del tío de Ponce. Este segundo sueño se produce después de la vuelta de su padre, a quien considera un extraño, porque lo había abandonado dos años antes en una noche de gritos. En este sueño, busca la amistad de «Dios» después de que se ha inquietado por oír de su padre que es ateo y por oír de su tía que su padre es «el hombre más malo del mundo» [Pérez Galdós, 1907: 184].

En la ilusión visual, que es un síntoma disociativo de despersonalización, ve su cuerpo como si no le perteneciera, en otro lugar, o fuera de sí mismo. Como efecto del acoso escolar, Luis se ve como el gato que tiene Abelarda a sus pies. Se ve como gato, en lugar de como persona, porque cree literalmente en el mote "Miau», que le hace infravalorarse hasta despersonalizarse. Esta percepción minusvalorada de sí mismo se convierte en irritabilidad cuando al oír de su padre que su abuelo es llamado "señor Miau», Luis insulta a su maltratador Paco en clase. Las injurias se vuelven a escenificar en la cuarta pesadilla con Paco, de una y otra parte, a pesar de que Paco muere. Según el psiquiatra Grisolle, en la sección sobre el monodelirio, hay quienes «se creen convertidos en animales» [1857: 219], pero esta ilusión visual no se convierte en delirio. 


\section{SÍNTOMAS DE EVITACIÓN DEL TRAUMA}

El tercer síntoma de los trastornos por estrés es la evitación deliberada del recordatorio de la amenaza a la vida de su abuelo, o la suya propia, dadas las agresiones que indirectamente ocasiona su padre y la difamación del padre sobre su abuelo. Luis realiza esfuerzos por evitar objetos que le simbolizan el trauma del cese de su abuelo, como la escultura del Cristo de la iglesia. La imagen representa el miedo a que su abuelo sea cesante o mendigo permanente por «culpa del ministro» [Pérez Galdós, 1907: 386]; el pavor a la oscuridad [Pérez Galdós, 1907: 47]; el miedo a los labios negros que vio en la cara de Paco enfermo [Pérez Galdós, 1907: 240], los cardenales negros de las lesiones de Cristo [Pérez Galdós, 1907: 320] y el ratón negro que sale de la boca de Paco; el terror al abuelo, que se da golpes fuertes en la cabeza por saber del ascenso de su yerno [Pérez Galdós, 1907: 299]; el miedo a la abuela que dice que «Dios» se enfada si se le pone «cara de palo» [Pérez Galdós, 1907: 75]; el temor a la tía Quintina, de quien la abuela comenta que lo va a robar y vender al extranjero [Pérez Galdós, 1907: 141]; el miedo al padre Víctor, que su abuelo ve como un «monstruo» [Pérez Galdós, 1907: 232] y que para Abelarda es un «hombre malo» que necesita convertirse a Dios [Pérez Galdós, 1907: 103], el temor al maestro que lo castiga por distraerse en clase [Pérez Galdós, 1907: 81], y el recelo al compañero de clase que lo apedrea y le insulta con el mote «Miau» en el colegio [Pérez Galdós, 1907: 82], y en su casa, poco antes de morir [Pérez Galdós, 1907: 240].

\section{SÍNTOMAS EMOCIONALES}

Entre las alteraciones emocionales de los trastornos por estrés, los sentimientos negativos, como la furia y el pánico se intensifican en sus sueños y pesadillas y, al despertar, Luis actúa motivado por estos sentimientos. Por ejemplo, el castigo deseado para Paco en la prime- 
ra pesadilla se materializa en la pelea con él, que Luis siente que es aprobada por «Dios» como un acto de valentía. Con la enfermedad de Paco, continúan los arrebatos de ira puesto que a pesar de rezar a «Dios» para que lo cure, considera que el tifus es un castigo divino para su madre, de quien se burla discriminándola por su género y clase social, en una actitud que copia de su padre. Este estado emocional derivado del maltrato administrativo del abuelo causa malestar y deterioro en las relaciones personales porque priva a Luis de sentir empatía por la enfermedad física o mental ajenas. En particular, Luis siente rabia contra Paco cuando sabe que está enfermo y siente desprecio por la vida de su abuelo, cuando conoce la pérdida de su empleo. En términos de la influencia negativa de su entorno escolar y familiar, Luis es mensajero de las ansiedades de Paco y su abuelo porque, de un lado, imita a Paco al pelear sintiendo deseos incesantes de venganza, como su acosador, y, por otro lado, repite la idea del abuelo sobre la muerte como liberación el día que el abuelo comenta la muerte de Paco [Pérez Galdós, 1907: 268].

\section{SÍNTOMAS COGNITIVOS}

Las alteraciones cognitivas de los trastornos por estrés incluyen el aturdimiento, la dificultad para concentrarse en los estudios y las alteraciones del sueño por las que la ansiedad le impiden conciliar el sueño. Hay sueños pesados, sueño inquieto y pesadillas recurrentes, que ya existían antes del tiempo de la novela. Prevalecen emociones negativas, como el estupor, el miedo, la ira, la culpa, la vergüenza y la tristeza, sobre la capacidad de afecto. Por ejemplo, la primera vez que Luis oye decir a su padre que es ateo, se angustia y siente los síntomas precursores. La segunda vez, imita el acto agresivo que vio en su abuela y le lanza un pedazo de pan antes de gritarle una injuria.

El cambio cognitivo más perjudicial de Luis es la visión negativa del mundo y de sí mismo, de forma que se disminuye su capacidad 
para la ternura y la compasión hasta el punto de que pierde la empatía por la supervivencia o la vida de su abuelo. Los sentimientos positivos de afecto quedan al margen hasta llegar a tener ideas suicidas, que, proyectadas sobre una profecía divina, acaban por convencer al abuelo de tomar la decisión de quitarse la vida. Luis había oído a su abuelo su opinión de que la muerte era una liberación de esta vida cuando la familia supo de la muerte de Paco: «Villaamil entonó al difuntito la oración fúnebre de gloria, declarando que es una dicha morirse en la infancia para librarse de los sufrimientos de esta perra vida» [Pérez Galdós, 1907: 268]. Este es un ejemplo donde, como su madre, «de escaso mundo y discernimiento de la vida» [Pérez Galdós, 1907: 130], absorbe lo que oye en su ambiente, lo procesa en sus visiones, y lo termina creyendo literalmente para transmitirlo como verdad absoluta. El niño no puede aprender de un modelo edificante.

\section{EVOLUCIÓN POR ESTRÉS AGUDO Y POSTRAUMÁTICO}

En el proceso de aceptación traumatizada de la noticia del cese del abuelo, se encuentran tres fases de ansiedad: una primera fase de trastorno por estrés agudo y dos fases de trastorno por estrés postraumático. Abuelo y nieto reducen el valor de la vida del abuelo con el cargo administrativo y la ansiedad por el cese irreversible imposibilita la comunicación y afecto entre ellos. Con cada fase, se debilita la esperanza por la vida del abuelo.

La primera fase, de estrés agudo, está formada por cinco visiones intrusivas al experimentar el terror al cese del abuelo en el trauma personal del acoso escolar. Las visiones incluyen la ilusión visual de verse como gato, la alucinación de ver insectos en las letras de su libro, las dos semi-pesadillas en que Luis cree que su fracaso escolar es el motivo del cese del abuelo y el sueño compensatorio del regalo de los anillos por pelearse, que, en realidad, no resuelve el deseo de venganza de Luis contra Paco. 
La segunda fase de estrés y primera etapa de estrés postraumático, comienza con el deseo incesante de venganza de Luis contra Paco, según revive el sentimiento de abandono por su abuelo y padre. En esta fase, la figura paternal de «Dios», no se le aparece por mucho que se autosugestiona y nota los síntomas precursores. Las tres alucinaciones en las que no encuentra la figura divina o solo la ve en parte son: (1) la alucinación durante la fiebre de un catarro en la que ve la ropa de «Dios» flotando, pero no su cara. Aquí se enfada, primero consigo mismo, pensando que «Dios» lo castigaba con su ausencia por no estudiar, y luego, con la deidad porque, según su lógica, no lo ha curado para poder estudiar y ayudar a su abuelo; (2) la alucinación en la que Luis razona equivocadamente que «Dios» se ha ido al lecho de muerte del tío de Ponce; y (3) la alucinación en la iglesia donde cree que ha visto a «Dios» caminando por la sacristía, aunque luego lo pone en duda. El deseo frustrado de contacto con «Dios» se materializa en arrebatos de ira e insultos contra Paco en clase, después de oír que su abuelo es caricaturizado en la oficina.

La tercera fase y segunda etapa de estrés postraumático, se compone de cinco visiones donde la figura de «Dios» no le ayuda: tres alucinaciones tras pesadillas donde no aparece «Dios» y dos pesadillas donde aparece, pero Luis siente el peligro del acoso y cese del abuelo en forma de acoso del compañero de clase. En la primera alucinación, desea la protección de «Dios» pero, en lugar de verlo, se ve a sí mismo, como soñador del sueño donde aparecería «Dios» tal y como había sucedido en ocasiones anteriores. En la segunda alucinación, aparece un ratón que sale de la boca de Paco, fantasea con que su padre lo defiende del mote «Miau», y su tía ocupa el rol de madre. Después, tiene una pesadilla en la que Paco revive para acosarlo, Luis y Paco se insultan y Luis oye el mote «Miau» a gritos, como la primera vez, pero de manera magnificada. Tras la noticia del ascenso del padre, que enoja a su abuelo, el 
nieto percibe una alucinación sobre los clavos de Cristo, en señal del ataque a su abuelo. Ve los clavos que hieren mortalmente a un Cristo sangrante en la cruz como recordatorio de la humillación propia y la de su abuelo. En la última pesadilla, tras ser sometido al maltrato de Abelarda, y en recuerdo de la actitud indiferente de su madre que renegó de él, Luis cree acepta fríamente que su abuelo se muera.

\section{ESTRÉS AGUDO: DEL MIEDO A LA PRIMERA PELEA}

En la primera fase de esperanza por la restitución del cargo del abuelo o negación más fuerte del cese, Luis identifica el acoso laboral del abuelo con el acoso escolar en dos visiones de animalización, dos semi-pesadillas y un sueño. Los ejemplos del texto corresponden a: (1.1) la explotación de Luis como cartero, la consecuente negligencia educativa y la autoinculpación del cese por no rendir en la escuela; (1.2) el acoso escolar y las alteraciones sensoriales; y (1.3) el acoso verbal y los castigos del maestro con arrebatos de ira por el intento fracasado de aparentar ser tan «valiente» o «ciego de ira» [Pérez Galdós, 1907: 82] como su acosador Paco.

\subsection{EXPLOTACIÓN COMO MENDIGO YAUTOINCULPACIÓN}

El primer capítulo de la novela ilustra la negligencia de tipo material sufrida por Luis a raíz del cese del abuelo. A la vecina Paca Mendizábal le dan lástima las hambres y el frío que pasaba Luis. La mala administración de los gastos de la casa de la abuela y la falta de ingresos originada por el cese del abuelo hacen que el niño sea explotado como cartero para mendigar limosnas o pedir recomendaciones por carta para la familia. Los intentos son vanos, pero la abuela le obliga a repartir las cartas a largas distancias en invierno, privándole de asistir 
a la escuela o de estudiar en casa por la tarde. Un día, la abuela le encargó el reparto el mismo día que el niño había asistido al funeral de cuerpo presente y el entierro de su compañero de clase.

Como consecuencia de la explotación del niño como mendigo con el fin de ayudar a su abuelo, Luis experimenta dos semi-pesadillas. La tristeza se vuelve ansiedad cuando después de ser acosado en la escuela, no puede concentrarse en las lecciones o cuando después de ser privado de la asistencia escolar, no sabe sus lecciones. En la primera semi-pesadilla, habiendo pedido sin éxito una limosna a Urbanito Cucúrbitas, Luis siente que se va a desmayar cuando pasa por un convento y recuerda a un mendigo que solía pedir por allí. Luis se imagina una mirada paternal y benevolente de un señor que se autoidentifica como «Dios» sin serlo. Luis imagina que, si estudia, «Dios» colocará a su abuelo y oye de «Dios»: «-Es menester que estudies, que te fijes en lo que lees y lo retengas bien. Si no, andamos mal; me enfado contigo, y no vengas luego diciéndome que por qué no colocan a tu abuelo...» [Pérez Galdós, 1907: 31-2]. En la segunda semipesadilla, Luis se siente culpable del cese de su abuelo: «Ya ves cuán abatido está el pobre señor, esperando como pan bendito su credencial. Se le puede ahogar con un cabello. Pues tú tienes la culpa, porque si estudiaras...» [Pérez Galdós, 1907: 88]. Joaquín Ingelmo y José Antonio Méndez [2013] explican el sentimiento de culpa de Luis como medida de defensa ante la falta de control sobre el cese de su abuelo. En efecto, pensando en un objetivo realizable y específico, que también se puede medir en el tiempo, Luis cree controlar el estrés por el trauma del cese.

\subsection{ACOSO ESCOLAR Y ALTERACIONES VISUALES}

Para denunciar la violencia contra Luis en la escuela, la primera escena de la novela Miau se refiere a los acosadores como un tropel, es decir, una parte del ejército está en su contra. La novela comienza a 
la salida del colegio de educación primaria describiendo el acoso verbal y físico por parte de una cuadrilla liderada por Paco Ramos contra Luis Cadalso. Luis huye, solo y silencioso, sin provocar a nadie, pero algunos escolares le cogen del brazo. Después, uno restriega y ensucia la cara de Luis con el fin de humillarlo en público. Luis escapa corriendo, lo persiguen y «dos o tres de los más desvergonzados le tiraron piedras, gritando Miau; y toda la partida repitió con infernal zipizape: Miau, Miau» [Pérez Galdós, 1907: 7].

Este comportamiento violento es un ejemplo de acoso escolar, según la definición de Dan Olweus [1991] porque es intencionadamente dañino, repetido, sin provocación de la víctima y con un desequilibrio de poder, como demuestra el carácter inofensivo perfilado por el narrador al principio de la novela: «El pobre chico de este modo burlado [...] era bastante mezquino de talla, corto de alientos, descolorido [...] tan tímido que esquivaba la amistad de sus compañeros, temeroso de las bromas de algunos, y sintiéndose sin bríos para devolverlas» [Pérez Galdós, 1907: 7].

En la misma página, el narrador enumera los sentimientos que le impidieron salvaguardar el honor de su familia: indignación, vergüenza y aturdimiento, emociones clave que causan una baja autoestima que Luis somatiza en la ilusión visual de ver su cuerpo identificado con el del gato que ve a los pies de Abelarda en su casa. Luis no distingue el animal doméstico de su persona porque en su mente, hay una convicción delirante de la realidad de la ilusión visual. Luis cree verificar la realidad:

Luis miraba a su abuela, a su tía mayor, a su tía menor, y comparando la fisonomía de las tres con la del micho que en el comedor estaba [...], halló perfecta semejanza entre ellas. Su imaginación viva le sugirió al punto la idea de que las tres mujeres eran gatos en dos pies y vestidos de gente, [...]; y esta alucinación le llevó a pensar si sería él también gato derecho y si mayaría cuando hablaba. De aquí pasó rápidamente a hacer la observación de que el mote puesto a su abuela y tías en el paraíso del Real, era la cosa más acertada y razonable del mundo [Pérez Galdós, 1907: 14]. 
En este proceso, interviene el sesgo cognitivo de confirmación para buscar información exterior que confirme su creencia emocional en el apodo. Junto a esta reacción disociativa en que no se reconoce a sí mismo como persona, se da una falta de concentración en los estudios y una alucinación por la que no reconoce su entorno como real. La dificultad para concentrarse se debe al impacto del acoso escolar y el acoso de su primera visión, que al igual que despierta su curiosidad, le causa malestar. El pelotón que se había abalanzado sobre Luis a la salida del colegio, ahora es dirigido por él en su alucinación durante el estudio. Se figura que él es un general y que los libros están a sus órdenes, pero cuando se pone a leer, las letras las ve como insectos que se mueven y Luis no puede atrapar el significado de las palabras: "Veía las letras hormiguear sobre el papel iluminado por la luz de la lámpara colgante. Parecían mosquitos revoloteando en un rayo de sol. Cadalso leía algunos renglones. "¿Qué es adverbio?" Las letras de la respuesta eran las que se habían propuesto no dejarse leer, corriendo y saltando de una margen a otra» [Pérez Galdós, 1907: 41]. Mediante el juego bélico, por el que termina doblando el pico de cada página de su libro, Luis revive la violencia escolar, a la vez que expresa su frustración por no poder comprender lo que lee.

Mediante la ilusión visual de verse como un gato, Luis reexperimenta la tristeza que persigue la intimidación de Paco. En la primera semi-pesadilla con «Dios», el niño revive la vergüenza de recibir el mote como la verdad absoluta, porque a «Dios» le hace gracia el mote y le manda «callar y aguantarse» [Pérez Galdós, 1907: 32]. Luis asume la deshonra de la burla escolar, la cual le entristece y avergüenza, al principio, y le enfurece, de manera irreversible, al final de esta fase. 


\subsection{ACOSO VERBAL, MALTRATO DEL MAESTRO Y PRIMERA PELEA}

El niño muestra un temprano desarrollo de agresividad por la pérdida de la dignidad familiar mediante el mote «Miau», por la pérdida del cargo del abuelo y por su fracaso escolar. La difamación de su familia le causa arrebatos de ira, alteración del sueño y dos semipesadillas donde se entristece por el rechazo a su abuelo y se avergüenza por no saberse la lección: tras el ataque a la salida de la escuela, y tras el incidente y pelea con Paco. Después de oír el mote «Miau», quedar impactado por la ilusión de verse un gato y percibir la alucinación de los insectos mientras leía, Luis cree oír a "Dios» decir de Paco que es un «ordinario, mal criado» [Pérez Galdós, 1907: 32] que merece ser castigado con una guindilla en la lengua y a ponerse en cruz media hora en clase, por castigo del maestro.

En un incidente en clase, Paco, el compañero en la travesura, le había acusado a Luis de llevar a clase unos anillos de puros de colores que le cuestan a Luis un insulto por parte del maestro y un castigo. Acto seguido, Luis y Paco se pelean, fuera de clase. A continuación, tiene un sueño que compensa los castigos concentrados en Luis por parte del maestro: el insulto «Miau», los golpes y la ruptura del juguete de Luis. En su sueño, los anillos de juguete se vuelven anillos que parecen de oro y piedras preciosas, un regalo significativo para la negligencia material que atraviesa la familia. Además, Luis ve el regalo de los anillos como un premio, que unido a que cree oír de «Dios» un halago sobre su valentía, convierten este sueño en un acto de triunfo que, sin embargo, vuelve más agresivo a Luis.

Luis es objeto del acoso verbal y castigo corporal del maestro. El maestro lo desprecia con el mote «Miau» y le da coscorrones y otros golpes: «-Miau es un hipócrita—dijo el maestro, y Cadalso no supo contener su aflicción oyendo en boca de D. Celedonio el injurioso apodo. Soltó el llanto sin consuelo, y toda la clase coreaba 
sus gemidos, repitiendo Miau, hasta que el maestro ipim, pam! repartió una zurribanda general, recorriendo espaldas y mofletes, como el fiero cómitre entre las filas de galeotes, vapuleando a todos sin misericordia» [Pérez Galdós, 1907: 81]. Estos castigos, que se suman a la práctica de situar a todo estudiante que no memoriza la lección del día «confinado al último puesto de la clase en señal de desaplicación e ignorancia» [Pérez Galdós, 1907: 79]. Son métodos disciplinarios, que, según recuerda Salvadora Luján-Ramón [2017], abusan del miedo a la humillación y al escarmiento. Después del castigo, Luis decide pelearse con Paco, lo que inicia un deseo de venganza insaciable.

La conducta de Luis imita la agresividad de su compañero Paco, su maestro y su familia. Estos arrebatos de ira son ignorados en casa. Por ejemplo, la abuela no se da cuenta del «sofoco» de Luis tras pelearse en la escuela [Pérez Galdós, 1907: 84]. Luis no cuenta a su familia la pelea con Paco porque cree que «Dios» lo ha llamado valiente. Así, se aísla en sus visiones y confía en ellas, como sustituto de una relación personal con sus cuidadores. A una edad en que no ha desarrollado la capacidad crítica y sin referentes morales en casa o en el colegio para enfrentar el acoso escolar de otras maneras, el mote «Miau» cambia el carácter de Luis desde el niño tímido e inofensivo de la primera página hasta el niño acosador que solo siente furia y aprende a no sentir empatía por los demás, ni siquiera, en los momentos más vulnerables de Paco, enfermo, o de su abuelo, angustiado al límite.

\section{ESTRÉS POST-TRAUMÁTICO: CARENCIA AFECTIVA Y PÉRDIDA DE EMPATÍA}

En esta etapa de estrés postraumático, hay alucinaciones en que se produce el abandono de «Dios» y se añaden arrebatos de ira relacionados con abusos como: (2.1) la negligencia afectiva del abuelo y del 
padre; y (2.2) la exposición a la enfermedad infecciosa y el acoso del maltratador Paco. Esta fase se caracteriza por el decaimiento de la esperanza y la progresiva pérdida de la empatía por la vida de su abuelo sustituyendo los sentimientos positivos por la furia dirigida contra «Dios» y contra Paco. De hecho, Luis interpreta la enfermedad de Paco como castigo divino por llamarle «Miau».

\subsection{NEGLIGENCIA AFECTIVA Y DEPENDENCIA DE LAS ALUCINACIONES}

Junto a la intranquilidad por el cese en su abuelo, que se muestra en la pregunta reiterada de cuándo van a colocar a su abuelo, Luis recuerda la negligencia afectiva del padre en dos alucinaciones y un sueño compensatorio. La alucinación de un «Dios» sin rostro expresa un primer momento de privación afectiva de su amigo imaginario. A pesar de los cuidados que recibe el día que tiene catarro gástrico, el niño quiere la compañía de su amigo divinizado y se frustra porque solo lo ve en parte. Luis se pone a recordar los lugares donde había visto a «Dios» mientras mira un cromo con la figura de «Dios». En su alucinación, solo ve el cuerpo y se siente triste y abandonado: «Cadalsito se había imaginado estar en el pórtico de las Alarconas o en el sillar de la explanada del Conde-Duque; pero no veía a Dios, o, mejor dicho, solo le veía a medias. Presentábasele el cuerpo, el ropaje flotante y de incomparable blancura; a veces distinguía confusamente las manos, pero la cara no. ¿Por qué no se dejaba ver la cara? Cadalsito llegó a sentir gran aflicción, sospechando que el Señor estaba enfadado con él» [Pérez Galdós, 1907: 159].

Luis comparte el abatimiento y la rabia de su abuelo al oír de $\mathrm{Pu}$ ra que su abuelo no aparece en la nueva plantilla de personal.: «Parecióle al chico que Villaamil sufría en silencio una gran pena [...] Estas palabras, impresas en la mente del chiquillo, las relacionó luego con la cara de ajusticiado del abuelo cuando entró a verle. 
[...] Si no hubiera conocido a su abuelo como le conocía, le habría tenido miedo en aquella ocasión, porque en verdad su cara era cual la de los ogros que se zampan a las criaturas» [Pérez Galdós, 1907: 161]. En un arrebato de ira contra «Dios», Luis se queja de no ser curado para poder estudiar y así ayudar a su abuelo: «"Pues si no le quiere colocar, no sé por qué se enfada Dios conmigo y no me enseña la cara. Más bien debiera yo estar enfadado con él"» [Pérez Galdós, 1907: 161].

Su padre le regala un álbum de sellos para que se entretenga mientras tiene el catarro, pero no responde con interés cuando el hijo le hace preguntas sobre los sellos. En este sueño compensatorio, abraza su álbum y espera mucho tiempo a tener la visión, desorientado: «No sufrió aquella noche el acceso espasmódico que precedía a la singular visión del anciano celestial. Pero soñó que lo sufría, y, por consiguiente, que deseaba y esperaba la fantástica visita. El misterioso personaje hizo novillos, y así lo expresaba con desconsuelo Cadalsito, deseando enseñarle su álbum» [Pérez Galdós, 1907: 184-5]. Para compensar su soledad, recurre a su «Dios» imaginario y justifica su ausencia diciendo que «Dios» se ha ido al lecho de muerte del tío de Ponce.

En búsqueda de figuras de amparo, Luis se autosugestiona para ver a «Dios» en la iglesia, en la siguiente alucinación: «Más de una vez se dijo que en tal sitio, a poco que se adormilase, había de ver al Señor de la barba blanca, por ser aquélla una de sus casas. Pero cerraba los ojos, haciendo como una mental evocación de la extraordinaria visita, y esta no se presentaba. En alguna ocasión, no obstante, creyó ver al augusto anciano saliendo por una puerta de la sacristía y perdiéndose en el altar, como si se introdujera por invisible hueco» [Pérez Galdós, 1907: 224]. Como efecto de la carencia afectiva, Luis duda sobre la presencia de un «Dios» visible en la iglesia. El abuelo se encierra en su desesperación por la credencial. Una muestra de su excesiva preocupación por la futilidad de sus intentos por recuperar su pensión 
es que desatiende a su nieto y no piensa en sus necesidades afectivas. Solo besa a su nieto cuando va a despedirse para siempre. Por este motivo, la mirada ansiosa de su abuelo se transforma en una mirada cariñosa y sonriente cuando Luis se imagina a su «Dios», quien le dice que lo quiere mucho [Pérez Galdós, 1907: 30], las manos de su abuelo que dan puñetazos en la mesa o portazos después de medianoche se tornan manos fuertes pero finas [Pérez Galdós, 1907: 30], y los tirones que le da a su nieto para desvestirlo se convierten en caricias en el último diálogo con «Dios».

\subsection{FALTA DE PIEDAD COMO TESTIGO DE LA ENFERMEDAD Y MUERTE DE PACO}

Privado de mucho afecto, Luis no solo no puede desprenderse de la ira contra su acosador, sino que pierde la compasión que el narrador juzga debería sentir por Paco: (1) cuando visitó al enfermo: «El sentimiento de piedad hacia su compañero no era tan vivo como debiera, porque el mameluco de Ramos le había insultado, arrojándole a la cara el infamante apodo, delante de gente. La infancia es implacable en sus resentimientos, y la amistad no tiene raíces en ella [Pérez Galdós, 1907: 245]; (2) en su funeral, cuando piensa que Paco no le llamará más Miau «como voz del egoísmo, más categórico en la infancia que la piedad» [Pérez Galdós, 1907: 277]; y (3) cuando Luis comenta la noticia de la muerte de Paco a su familia «con más acento de novelería que de pena, condición propia de la dichosa edad sin entrañas» [Pérez Galdós, 1907: 268]. Así se relatan tres pérdidas del sentimiento de piedad de Luis por Paco.

El nieto revive el terror y la furia que siente su abuelo de no ser seleccionado para la nueva plantilla de personal. El efecto emocional será el de perder la piedad inicial por la enfermedad y muerte de Paco después de experimentar tres visiones, una noche insomne tras ser testigo de la enfermedad grave de su acosador Paco, y una pesadi- 
1la, después de asistir a su funeral de cuerpo presente. En concreto, Luis va a sentir que la enfermedad es un castigo para la madre por inventar el mote [Pérez Galdós, 1907: 241].

Primero, en una alucinación, Luis se ve a sí mismo como soñador en necesidad de ver a «Dios» tras ver que Paco «tenía los ojos, aunque inflamados, mortecinos, los labios tan cárdenos que parecían negros [...] Cadalso sentía lástima y también terror instintivo que le mantuvo desviado de la cama» [Pérez Galdós, 1907: 240]. Por la noche no puede conciliar el sueño: «Habíase acostado con el deseo de ver a su benévolo amigo, el de la barba blanca; los síntomas precursores se habían presentado, pero la aparición no. Lo doloroso para Cadalsito era que soñaba que la veía, lo que no era lo mismo que verla» [Pérez Galdós, 1907: 242].

Segundo, en una pesadilla, Luis revive el sentimiento de abandono de «Dios», lo que provoca la pérdida de compasión por su abuelo y el aumento de la furia contra su compañero. Como sucedió en la vigilia, con la contradicción entre rezar por la curación de Paco y estar resentido, persiste el deseo de castigo divino para Paco y le dice a «Dios»: «Le castiga usted por malo, por poner motes» [Pérez Galdós, 1907: 243], enunciado que aterra a Abelarda, que atenta a sus palabras, mientras tiene su pesadilla con Víctor, cree que el enunciado se refiere a las burlas de Víctor.

Tercero, hablando con Abelarda, Luis ve una alucinación y llama a «Dios» para que ponga un castigo a Paco. El enfermo se convierte en amenaza aterradora porque de su boca negra, la que había visto en su visita al enfermo, sale un ratón, símbolo del mote «Miau» que dirigió Paco a Luis mientras agonizaba: «Es un ratón lo que Posturas echa por la boca, un ratón negro y con el rabo mu largo. Me escondo debajo de la mesa. [...] Pero mi papá lo ha cogido. ¿No ves a mi papá?» [Pérez Galdós, 1907: 244]. En su rescate, imagina a su padre, de quien pensaba que daba miedo por lo que su familia decía de él. Creyendo que las declaraciones de amor que había escuchado de su padre a su tía eran honestas, 
Luis propone a su tía que se case con su padre, en una recomposición idealizada de los padres que perdió: su madre que murió y su padre que lo abandonó al cuidado de los abuelos maternos. Le dice a Abelarda: «y mi papá estaba acostado contigo, y cuando yo le llamé vino a cogerme [...] -Dime otra cosa. ¿Y mi papá se va a casar contigo?» [Pérez Galdós, 1907: 244-5]. En esta alucinación alarmante, ignora que su padre tenía una amante aristócrata para conseguir un ascenso, y que su tía, habiendo sido abandonada cruelmente por Víctor, había pensado matar a hachazos a Luis [Pérez Galdós, 1907: 324].

Luis asiste al funeral de cuerpo presente y siente una mezcla de terror y pena ante «la boca entreabierta y de un tono casi negro» [Pérez Galdós, 1907: 276], pero decide que el difunto no se podrá mofar de él, ya enterrado. Sin embargo, el trauma del acoso emerge en una pesadilla cuando un arrebato de furia e insultos concluye con un grito de «Miau» contra Luis que retumba en el edificio del Congreso de los Diputados donde se queda dormido [Pérez Galdós, 1907: 287].

En la última pesadilla, Paco intenta ahogar a Luis tirando la bola azul del mundo al agua. «Dios» salva la bola y deja encerrado al acosador, en un acto de protección que no obtiene el niño en su vida real. Esta pesadilla, que cierra la experiencia traumática de ver la enfermedad y muerte de Paco, recuerda el ataque a la honra de su persona y de su abuelo. La sensación de impotencia ante el acoso incesante de Paco permite notar la futilidad de los arrebatos de ira por no perder el honor asociado al puesto en el Ministerio. Luis sale del Congreso con un nuevo rechazo, aunque seguirá preguntando en la siguiente fase de estrés, cuándo colocarán a su abuelo.

\section{ESTRÉS POSTRAUMÁTICO: DEL ATAQUE DE PÁNICO AL DESAPEGO}

En la última fase, se recrudece la falta de apego hacia su abuelo. El nieto revive el trauma del acoso que observa en su abuelo victimi- 
zado en el acoso escolar con que Paco le hostiga repetidamente. Luis siente un ataque de pánico en forma de una alucinación sobre los clavos de Cristo que ve tras una pesadilla, y se inclina hacia el deseo destructivo de una muerte prematura para su abuelo tras el último diálogo con «Dios» después de haber sido asaltado gravemente por su tía. La alucinación confronta a Luis con su mayor miedo en la iglesia, ver el Cristo de Monserrat. La alucinación le fuerza a ver la imagen en la que Luis concentra el peligro más aterrador del trauma de su abuelo. Hay dos situaciones postraumáticas: (3.1) la evitación del Cristo en la cruz en la iglesia; y (3.2) el deseo de muerte para su abuelo, tras el ataque físico y verbal perpetrado por su tía Abelarda.

\subsection{EVITACIÓN DE LA IMAGEN DE CRISTO YATAQUE DE PÁNICO}

La violencia gráfica del Cristo de la iglesia de Monserrat simboliza el acoso laboral del abuelo. El abuelo se indigna por constatar que él, como funcionario competente y honrado es cesado, mientras su yerno, favorecido por una amante aristócrata y habiendo desfalcado al Estado, es ascendido. Luis ya había dejado de ver la cara de «Dios» tras la vuelta del padre y se había enfadado por ello. Ahora, tras conocer por Abelarda, que su padre ha sido ascendido, Luis tiene una pesadilla y una alucinación sobre la victimización de su abuelo. El niño evita mirar al Cristo, que tiene una melena larga de pelo natural y el cuerpo lleno de sangre. El terror a tener una pesadilla con la imagen sagrada le espanta el sueño a Luis en la primera visita a la iglesia con Abelarda, cuando ambos pensaban que Víctor la quería. Esta es la reacción de pánico de Luis después de que su abuelo no aparece en la plantilla de personal de Contribuciones: «Hizo propósito de vencer el sopor, y se pellizcó los brazos diciendo: "iAy! icontro! Si me duermo y se me pone al lado el Cristo de las melenas, del 
miedo me caigo muerto". Y el miedo y los esfuerzos por despabilarse vencían al fin su insano sopor» [Pérez Galdós, 1907: 225].

En la iglesia, tras oír la noticia del ascenso de su yerno, comunicada al abuelo con «saña parricida» [Pérez Galdós, 1907: 298] por Abelarda por haber sido burlada por Víctor, el abuelo se da un golpe tan fuerte en la cabeza que Luis «se asustó, mirando consternado a su abuelo» [Pérez Galdós, 1907: 299]. El abuelo aterra al nieto cuando pasan por delante del Cristo diciéndole: «Que te come, tonto» [Pérez Galdós, 1907: 301]. Por la noche, Luis habla a su tía en un ataque de pánico y ve una alucinación con el Cristo. Luis afirma: «Yo veo a Dios, lo veo cuando me da la gana; para que lo sepas... Pero esta noche no le veo más que los pies... los pies con mucha sangre, clavaditos [...] y me da mucho miedo... [Pérez Galdós, 1907: 318-9].

El niño ruega no ver la sangre de Cristo: «—Tiíta, ahora le veo el faldellín todo lleno de sangre, mucha sangre...Ven, enciende luz, o me muero de susto; quítamele, dile que se vaya. El otro Dios es el que a mí me gusta, el abuelo guapo, el que no tiene sangre, sino un manto muy fino y unas barbas blanquísimas...» [Pérez Galdós, 1907: 321]. En esta expresión de angustia, el niño pierde la capacidad para la compasión por la vulnerabilidad de otras personas. Después de notar el abandono de la figura paternal, surge la consecuencia más peligrosa del trastorno, la pérdida de apego por su cuidador principal, el abuelo, que había ejercido la función de padre antes del cese.

\subsection{PÉRDIDA DEL APEGO POR EL ABUELO TRAS EL MALTRATO FÍSICO}

El abuso directo más perjudicial para Luis y su abuelo proviene de dos intentos de asesinato por parte de su madre, a los dos años, y de su tía, a los nueve años, por delirios de celos causados por las infidelidades negadas de Víctor. La madre ataca al hijo: «Aquella mañana [...] se arrojó del lecho pidiendo un cuchillo para matar a Luis. Jura- 
ba que no era hijo suyo» [Pérez Galdós, 1907: 132]. Por la amnesia del trauma, Luis se entristece solo por imitación de su familia al oír hablar de ella "pues había notado que cuando alguien pronunciaba en la casa el nombre de su mamá, todos suspiraban y se ponían muy serios» [Pérez Galdós, 1907: 97]. Luis llora cuando le ataca verbal y físicamente su tía. Cuando su abuelo y su padre le engañan minimizando el ataque como una «broma un poco pesada» [Pérez Galdós, 1907: 373] deja de sollozar, pero la violencia de Abelarda contra Luis es grave:

Abelarda tendió un brazo, que parecía de hierro, y de la primera manotada le cogió de lleno a Luis toda la cara. El restallido debió de oírse en la calle. Al hacerse para atrás, vaciló la silla en que el chico estaba, y ipataplúm!, al suelo. [...] Ciega y salvaje, de un salto cayó sobre la víctima, clavándole los dedos furibundos en el pecho y en la garganta [...] «Perro, condenado... te ahogo! iEmbustero, farsante... te mato!», gruñía [Pérez Galdós, 1907: 370-1].

El niño responde a su abuelo sobre el abuso que no es un riesgo vivir con Abelarda porque ella se casa con Ponce y no con su padre, quien la enfureció cuando supo que Víctor le dijo al ministro que no colocara al abuelo [Pérez Galdós, 1907: 386]. Más tarde, Luis recapacita y no quiere convivir con ella. En réplica a la amenaza de muerte de Abelarda contra él, Luis no reconoce a su abuelo como una figura de apego, y amenaza verbalmente al abuelo ofendiendo al familiar más frágil para defenderse del maltrato de otro familiar más violento. Luis se hace cómplice del suicidio de su abuelo, después de denigrarlo por su edad y situación laboral. En el diálogo con «Dios», se niega a que su abuelo se muera, pero acepta que «Dios» determine el cese y la muerte del abuelo después de oír que si va a ser cura, va a tener que predicar que «el mundo es un valle de lágrimas, y mientras más pronto salís de él, mejor» [Pérez Galdós, 1907: 388]. Luis traslada esta supuesta conversación a su abuelo y le dice «que este mundo es muy malo, y que tú no tienes nada que hacer en él, y que cuanto más 
pronto te vayas al cielo, mejor. [...] Pues, eso me dijo...que morirte pronto es lo que te conviene, para que descanses y seas feliz» [Pérez Galdós, 1907: 404]. Esta idea delirante que confunde ideas propias con ideas divinas es un síntoma ajeno al trastorno por estrés.

Durante los dos meses de respuesta al trauma del cese del abuelo, las visiones de Luis permiten detallar la evolución de los trastornos por estrés agudo y postraumático. En una primera fase de empatía de Luis con su abuelo, Luis interpreta que puede beneficiar a su abuelo con la ayuda de «Dios» mediante la aplicación en los estudios y la oposición al acoso de Paco mediante una pelea. En una segunda fase, el trastorno por estrés postraumático se caracteriza por la privación afectiva y desprotección de sus figuras paternales en sus alucinaciones. La tercera fase muestra el deseo implacable de venganza contra el acosador en la escuela, incluso después de que cae enfermo y muere. Luis interpreta la enfermedad de Paco como castigo divino y tras su muerte, cree oír que «Dios» ha encerrado a Paco en un lugar secreto y quiere verlo. Esta pérdida de la compasión por los demás es la reacción más destructiva para la salud de Luis y, resultará en una amenaza fatal para la vida de su abuelo.

\section{CONCLUSIÓN}

Se han contextualizado las visiones que recuerdan el trauma de la violencia que sufre Luis y presencia en su abuelo en una fase de trastorno por estrés agudo y dos fases de estrés postraumático, que conectan con siete situaciones de maltrato infantil. Como consecuencia del maltrato, el niño pierde la capacidad para valorar la vida de su abuelo, desde la negación del trauma del cese, revivido y evitado, hasta la pérdida de apego por el abuelo. En nueve de las visiones, Luis cree o desea ver a un mendigo que se identifica como «Dios» y que, responde a la voz irracional o instintiva del niño que actúa con violencia frente a la violencia. Las visiones intrusivas de Luis expre- 
san cambios fisiológicos, emocionales y cognitivos que desembocan en una ideación suicida que finalmente incita a la consumación suicida en su abuelo. La exposición temprana, intensa y recurrente al maltrato es un factor de riesgo para los trastornos de ansiedad. Galdós expone así a las víctimas del maltrato y muestra el peligro de que los niños respondan como victimarios. Por tanto, se interpreta que la novela urge a la protección para los niños, especialmente cuando el ambiente familiar y escolar, que debía darles seguridad, se torna contra ellos de forma violenta.

\section{BIBLIOGRAFÍA}

ARMANGUÉ y TUSET, José (1884): Estudios clínicos de Neuropatología, Barcelona, Sucesores de Ramírez y Ca.

Asociación AMERICANA DE PSIQUiATRÍA (2014): Manual diagnóstico e estatístico de transtornos mentais, Porto Alegre, Artmed.

CAZABAT, Eduardo H. (2004): «Evolución histórica del concepto de disociación", Revista de psicotrauma, 3 (1): 42-7.

GINÉ y PARTAGÁs, Juan (1876): Tratado teórico práctico de frenopatología o Estudio de las enfermedades mentales, Madrid, Moya y Plaza.

GrISOLLE, Augustin (1857): Tratado elemental y práctico de patología interna, Madrid, Gaspar y Roig.

INGELMO FERNÁNDEZ, Joaquín y José Antonio Menéndez Ruiz (2013): «Estudio de algunos sueños infantiles en Miau de Luis Cadalso», Revista de Psicopatología y Salud Mental del Niño y del Adolescente, 21: 8388.

LUJÁN-RAMÓN, Salvadora (2017): Imaginario pedagógico en la producción de Benito Pérez Galdós (Doctorado), Universidad de Las Palmas de Gran Canaria.

NueZ, Sebastián de la y José SCHRAibman (1967): Cartas del archivo de Galdós, Madrid, Taurus.

Olweus, Dan (1993): Bullying in the School: What We Know and What We Can Do, Oxford, Blackwell.

PéreZ Galdós, Benito (1907): Miau, Madrid, Universidad de Puerto Rico. (1889): «Prólogo» a La nochebuena de un médico de Niñerías, de Manuel Tolosa Latour, Madrid, Imprenta de los Hijos de M. G. Hernández. 
TURNER, Harriet S. (2000): «Creación galdosiana en el marco de la medicina», en Actas del XIII Congreso de la Asociación Internacional de Hispanistas, coords. Florencio Sevilla Arroyo y Carlos Alvar Ezquerra, (Madrid, Castalia), 2, 441-447.

Velasco Vargas, Magali (2004): «Los ocho sueños de Cadalsito en Miau de Benito Pérez Galdós», La Palabra y el Hombre: Revista de la Universidad Veracruzana, 129: 69-84. 